\title{
GRAD BEOGRAD KAO PRIMER DOBRE PRAKSE U UPOTREBI MODERNIH INFOMACIONO-KOMUNIKACIONIH TEHNOLOGIJA U KOMUNIKACIJI IZMEĐU GRAĐANA I GRADSKE VLASTI
}

\author{
Miloš Milenković1, \\ Dalibor Kekić2, \\ Darko Glavaš ${ }^{3}$
}

\author{
${ }^{1}$ Ministarstvo unutrašnjih poslova - \\ Sektor za vanredne situacije, \\ Omladinskih brigada 31, \\ Beograd, Srbija \\ ${ }^{2}$ Kriminalističko-policijska akademija, \\ Cara Dušana 196, \\ Zemun, Srbija \\ ${ }^{3}$ Grad Beograd - Sekretarijat za poslove \\ odbrane, vanrednih situacija, \\ komunikacije i koordinaciju odnosa sa \\ građanima, \\ Tiršova 1/IV \\ Belgrade, Serbia
}

Rezime:

Komunikacija između građana i gradske vlasti veoma je značajna, posebno u velikim gradovima. Građani žele da znaju šta se dešava, gde su se pojavili problemi i kada će biti rešeni. Sa druge strane, predstavnici gradske vlasti treba da steknu što veće poverenje kod građana, ukoliko im pružaju adekvatne informacije. Trenutn je na raspolaganju širok spektar informacionokomunikacionih tehnologija koje olakšavaju komunikaciju između građana i gradske vlasti. Posebna pažnja posvećuje se komunikaciji u slučaju vanrednog događaja ili situacije. Građani bi trebalo da imaju mogućnost da ukažu na problem na teritoriji grada. U slučaju hitnosti, kada je vreme ograničavajući faktor, upotreba modernih informaciono-komunikacionih tehnologija korisna je u delu koordinacije između građana i gradske vlasti. Grad Beograd, kao glavni grad Republike Srbije, primer je dobre prakse u ovoj oblasti. Gradska uprava Grada Beograda prepoznaje potrebu upotrebe modernih informaciono-komunikacionih tehnologija u komunikaciji sa građanima. Posebna organizaciona jedinica gradske uprave zadužena je za ove zadatke. U ovom poslu koristi se nekoliko aplikacija koje su dostupne građanima. Takođe, komunikacija može biti ostvarena i putem društvenih mreža.

Ključne reči:

gradska uprava, građani, informaciono-komunikacione tehnologije, Grad Beograd, društvene mreže.

\section{UVOD}

Komunikacija u savremenom društvu predstavlja veoma bitan segment u svakoj oblasti. Komunikacija se može definisati kao proces na osnovu koga neka osoba, grupa ili organizacija (pošiljalac) prenosi neku vrstu informacije (poruku) nekoj drugoj osobi , grupi ili organizaciji (primalac) [5]. Proces komunikacije počinje tako što pošiljalac određenu ideju, uz modifikaciju, prenosi komunikacionim kanalom do primaoca koji ideju prima, dekodira i po potrebi šalje povratnu informaciju. Danas ne postoji sfera poslovanja u kojoj se ne insistira na optimizaciji komunikacije. Resursi za realizaciju zadataka organičeni su i dobrom komunikacijom koja predstavlja osnov koordinacije, može se uspostaviti efikasna i efektivna upotreba dostupnih resursa i time ostvarenje zacrtanih ciljeva. Kao pomoćno sredstvo, bez koga se ne može ostvariti komunikacija u savremenom poslovanju, koriste se informaciono-komunikacione tehnologije. 
Informaciono-komunikaciona tehnologija, vrlo često označena skraćenicom ICT (information and communication technologies) sve češće se pominje u kontekstu poslovnih sistema. Akronim ICT često se zamenjuje akronimom IT (information technology). Informacione i komunikacione tehnologije možemo definisati kao skup tehnologija koje se koriste u procesu sakupljanja, odabira, verifikacije, obrade, skladištenja, prenosa, prikaza, objavljivanja i podele informacija, ili u procesima komunikacije [7]. Jedna od oblasti u kojima se prepoznaje značaj upotrebe informaciono-komunikacionih tehnologija jeste i komunikacija između građana i gradskih vlasti, odnosno uprave. Veliki gradovi širom sveta veliku pažnju posvećuju komunikaciji sa građanima i stalno nastoje da je unaprede, upravo korišćenjem savremenih informaciono-komunikacionih tehnologija. Grad Beograd, kao glavni grad Republike Srbije, takođe ulaže velika sredstva i napore kako bi komunikacija sa građanima bila što efikasnija i efektivnija i predstavlja primer pozitivne prakse.

\section{ORGANIZACIONA STRUKTURA SLUŽBE ZA KOMUNIKACIJU I KOORDINACIJU ODNOSA SA GRAĐANIMA GRADA BEOGRADA}

Grad Beograd svoju organizaciju temelji na radu nekoliko sekretarijata koji su zaduženi za uređenje pojedinih oblasti života i rada građana Beograda. Odnedavno u okviru gradske uprave funkcioniše i gradski sekretarijat za poslove odbrane, vanrednih situacija, komunikacije i koordinaciju odnosa sa građanima. U okviru ovog sekretarijata, kao zasebni organizacioni deo prepoznaje se služba za komunikacije i koordinaciju odnosa sa građanima, ili popularno „Beokom servis”. Služba za komunikacije i koordinaciju odnosa sa građanima - „Beokom servis” vrši stručne, operativne, organizacione i administrativno-tehničke poslove koji se odnose na komunikaciju sa građanima u vezi sa pružanjem usluga javno komunalnih preduzeća i drugih subjekata, koordinaciju odnosa između Gradske uprave, javno komunalnih preduzeća i drugih subjekata kojima je povereno obavljanje komunalnih delatnosti, saradnja sa informacionim centrima subjekata kojima je povereno obavljanje komunalnih delatnosti u cilju unapređenja njihovog odnosa prema građanima, priprema i izdavanje publikacija u oblasti ostvarivanja prava građana za pružanje komunalnih usluga, koordinaciju poslova javnih preduzeća i javno komulalnih preduzeća [2]. Iz navedenog može se zaključiti da se u Gradu Beogradu velika pažnja posvećuje komunikaciji sa građanima, a sve u cilju zadovoljenja njihovih potreba na svim nivoima. Takođe, u pogledu obezbeđenja životnih uslova na propisanim standardima veliku ulogu na teritoriji grada Beograda imaju javno komunalna preduzeća, poput JKP „Beogradski vodovod i kanalizacija”, JKP „Beogradske elektrane”, JKP „Gradska čistoća”, JP „Gradsko stambeno" i drugi. Oni su ključni segment svakodnevnog funkcionisanja vitalnih službi od kojih i zavisi kako će građani živeti. Sa druge strane, žiteljima Grada Beograda u interesu je da znaju svaki vid promene koje kreiraju pomenuta preduzeća, a može imati uticaj na njihov svakodnevni život. Na primer, ako dolazi do radova u nekim ulicama na teritoriji grada, ili će pojedine gradske ulice ostati bez vode ili električne energije, svakako da je građanima od velikog značaja raspolaganje informacijama o prethodno opisanim radovima. Gradska uprava Grada Beograda prepoznala je značaj komunikacije i koordinacije odnosa sa građanima u ovoj oblasti i iz tih razloga organizaciono izdvaja službu koja će se baviti tim poslovima. Danas, kako je i prethodno naglašeno, ova služba pripada sekretarijatu koji se pored poslova vezanih za komunikaciju i koordinaciju odnosa sa građanima, bavi i oblastima odbrane i vanrednih situacija.

Služba za komunikacije i koordinaciju odnosa sa građanima u okviru svoje organizacione strukture ima nekoliko organizacionih jedinica. Rad Službe za komunikacije i koordinaciju odnosa sa građanima organizovan je kroz dva sektora - Sektor „Beogradski pozivni centar”, u okviru koga se nalazi Odeljenje za nadzor i kontrolu, i Sektor „Informacioni centar” u okviru koga se nalaze Odeljenje za komunikacije, Odeljenje za praćenje, koordinaciju i upravljanje, Odsek za normativne, stručno-operativne, studijsko-analitičke i materijalno-finansijske poslove i Odsek za događaje [2]. Posmatrano kroz sve dimenzije organizacione strukture, Služba je organizovana na način da se postiže maksimalna efikasnost i efektivnost u komunikaciji sa građanima. Pored dobre organizacije, da bi se zacrtani ciljevi ostvarili, neophodno je u ovoj oblasti koristiti i savremene informaciono-komunikacine tehnologije, o čemu će biti reči u narednim poglavljima rada.

\section{INFORMACIONO -KOMUNIKACIONE TEHNOLOGIJE I APLIKACIJE KOJE KORISTI GRAD BEOGRAD U KOMUNIKACIJI SA GRAĐANIMA}

U ovom delu biće prikazan način upotrebe modernih informaciono-komunikacionih tehnologija u komunikaciji sa građanima na teritoriji Grada Beograda.

Odeljenje za komunikacije komunicira sa građanima putem društvenih mreža Fejsbuk i Tviter, aplikacija 
za mobilne telefone, medija poput televizije Studio B, Radio Lagune, Radio Beograd 202, Radio Studio B, Radio S, RTS, TV Naša i TV Kopernikus, kao i lično na pozive građana za zakazivanje sastanaka sa članovima Gradskog veća i gradonačelnikom [2]. Širok spektar mogućnosti za komunikaciju sa gradskim vlastima stavlja se na mogućnost građanima. U eri upotrebe mobilnih telefona, kompjutera i interneta, gradske vlasti nastoje da implementiraju korisne aplikacije kako bi neophodne informacije građanima bile dostupne uvek i bilo gde. Ako se posmatraju društvene mreže, poput Fejsbuka i Tvitera, statistika govori da je u periodu 2016. godine komunikacijom preko društvene mreže Tviter bilo 8960 tvitova, 1642 novih pratilaca, 1.464 .000 poseta profilu i 14.625 pominjanja, a zabeleženo je i 4459 prijava. Komunikacijom preko društvene mreže Fejsbuk, Odeljenju za komunikacije obratilo se sa prijavama 344 građana, postavljeno je 1938 objava, a stranica je imala 1660 pratilaca [2]. Prema navedenom, uočljiv je značaj upotrebe društvenih mreža u komunikaciji sa građanima. Većina građana u svakodnevnom životu koristi barem jednu od mnoštva aktuelnih društvenih mreža. Gradska uprava Grada Beograda, a preko svoje Službe za komunikaciju sa građanima, zaključila je da od velike koristi može biti korišćenje društenih mreža u cilju što bolje komunikacije sa građanima. Tako, na primer, preko Tvitera i Fejsbuka, građani mogu doći do korisnih informacija, ali takođe i prijaviti i neke probleme koje uoče i koji zahtevaju hitno rešavanje.

Mobilni telefoni koji se koriste daju mogućnost i upotrebe velikog broja aplikacija koje obezbeđuju dostupnost raznovrsnih informacija. Tako, na veoma brz i jednostavan način, građani Beograda upotrebom aplikacija na modernim i „pametnim” telefonima mogu doći do informacija o dešavanjima u gradu, poput sportskih dešavanja, kulturnih manifestacija i slično. Sa druge strane, korišćenjem ovih tehnologija, koje se mogu svrstati u kategoriju modernih informaciono- komunikacionih tehnologija, građani Beograda mogu saznati šta se dešava u gradu, a tiče se svakodnevnog života i komunalnih delatnosti. Trenutno je aktuelna aplikacija za mobilne telefone „Beokom”. Aplikaciju „Beokom servisa” koja je dostupna korisnicima mobilne telefonije mogu preuzeti i mobilni telefoni koji rade na IOS platformi („epl” uređaji) [2]. Preuzimanje ove aplikacije je besplatno. Ovom aplikacijom omogućava se brzo i lako prijavljivanje komunalnih problema u Gradu Beogradu. Na aplikaciji se objavljuju sve vesti vezane za komunalni sistem, razvojni projekti i modernizacija, najave radova koji će se obavljati na celoj teritoriji grada, kao i najave događaja koji će se odvijati u Beogradu. Korisnici mogu da pročitaju i servisne informacije jer se objavljuju svi planirani radovi gradskih javnih preduzeća i javnih komunalnih preduzeća. Pored svih pomenutih informacija, takođe, objavljuju se i informacije o izmenama režima saobraćaja u delovima grada gde se obavljaju radovi, kao i informacije od javnog značaja, ankete putem kojih sugrađani, korisnici aplikacije, mogu direktno da ocene funkcionisanje kako same aplikacije, tako i rad „Beokom servisa”, a u posebnom delu aplikacije dat je spisak svih brojeva telefona gradskih službi. Prijavljivanje problema je deo u kojem korisnici aplikacije jednostavnim registrovanjem sa lica mesta mogu prijaviti komunalni problem, sa fotografijom problema, koji se odmah, direktno, šalje u bazu „Beokoma" i prosleđuje nadležnoj službi, a sugrađanina koji je prijavio problem u najkraćem roku kontaktiraju operateri Beogradskog pozivnog centra radi eventualnih dodatnih informacija. Kada „Beokom servis” dobije odgovor od službe koja je nadležna i kojoj je problem prijavljen, korisnik aplikacije se telefonskim putem obaveštava o odgovoru [1]. Komunikacijom putem aplikacije za mobilne telefone „Beokom” u toku 2016. godine postavljeno je 1419 vesti i 2844 servisnih informacija. Ovu aplikaciju građani mogu besplatno preuzeti sa Google play store i sa App store. Sa Google play store je preuzeta 4550 puta, a sa I store platforme 195 puta [2].

Takođe, još jedna korisna i upotrebljiva aplikacija je aplikacija za mobilne telefone „Beograđani”. Stanovnici Beograda su ovom aplikacijom dobili šansu da daju predloge o uređenju parkova, javnih prostora, biciklističkih staza, unapređenju prevoza. Time se daje mogućnost da građani Beograda doprinesu daljem razvoju glavnog grada Republike Srbije i naseljenih mesta gde pojedinačno žive. Komunikacijom putem aplikacije za mobilne telefone „Beograđani” objavljeno je 115 vesti u 2016. godini. Ovu aplikaciju, koja se može besplatno preuzeti sa Google play store i sa App store, koristi 3120 građana [2]. „Beokom servis” raspolaže i sa internom bazom podataka na koju se mogu objavljivati i razne informacije vezane za svakodnevni život u Beogradu. U prethodnoj godini objavljeno je preko tri hiljade objava u okviru ove interne baze podataka. To dovoljno govori o značaju interne baze podataka koja se koristi u cilju komunikacije sa građanima Beograda. 


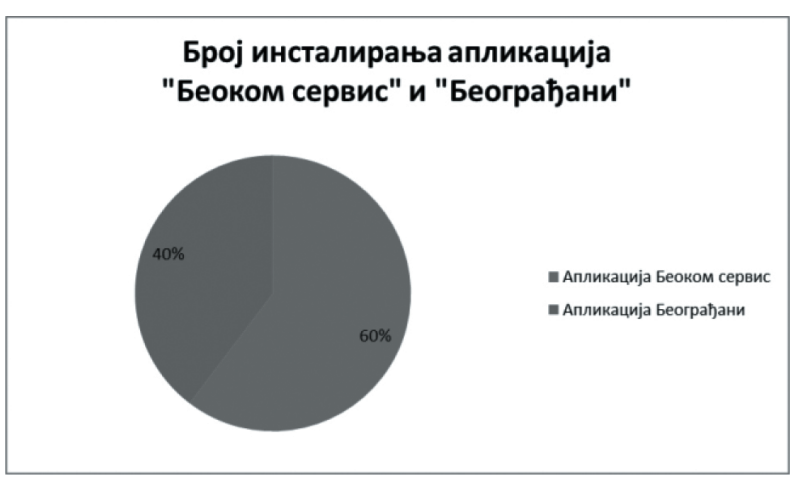

Slika 1. Broj instaliranja aplikacija u 2016. godini [2].

Građani do raznih informacija, a koje se tiču života na teritoriji grada Beograda, često dolaze i putem različitih vidova medija. Gradske vlasti Grada Beograda prepoznale su i ovaj vid komunikacije kao jedan izraženo važan segment u odnosu sa građanima. Nastoji se da se svakoj od medijskih kuća izađe u susret sa ažurnim informacijama. Međutim, kada je reč o upotrebi informaciono-komunikacionih tehnologija, naglasak u odnosu sa medijima je akutelni sajt Grada Beograda. Uvidelo se da većina medija koristi zvanične sajtove brojnih institucija, kako bi došli do aktuelnih informacija. U tom cilju, Služba za komunikacije i koordinaciju odnosa sa građanima nastoji da svakodnevno pruža ažurne informacija na zvaničan sajt Grada Beograda. Kasnije, mediji mogu to koristiti kao zvaničan izvor i preneti informacije građanima u cilju njihove informisanosti o aktulenom stanju u Gradu Beogradu.

Korišćenje informaciono-komunikacionih tehnologija karakteristično je i u okviru sektora „Beogradski pozivni centar”. Zaposleni u Sektoru „Beogradski pozivni centar” ostvarili su 126.621 poziva, od čega je 117.701 dolaznih poziva i 8.920 odlaznih poziva ka građanima, a od čega je kreirano ukupno 54.160 predmeta. Broj primljenih prijava putem e-maila je 795, putem „Beokom” aplikacije 1254, ostale prijave su primljene putem telefona. Od ukupnog broja kreiranih predmeta 27.368 je prosleđeno javno komunalnim preduzećima, javnim preduzećima i ostalim subjektima koji su nadležni za rešavanje, a 14.528 predmeta je bilo u nadležnosti Komunalne policije [2]. Kao što se vidi iz navedenih statističkih podataka, najdominantiji vid komunikacije sa ovim sektorom je putem telefona. Kada je reč o upotrebi informaciono-komunikacionih tehnologija koje su dostupne u radu ovog sektora, vidi se malo ušeće primljenih prijava putem e-maila, odnosno aplikacije. Međutim, očekuje se da u budućnosti bude sve veća upotreba „Beokom” aplikacije za prijavu komunalnih problema.

\section{Број примљених пријава}

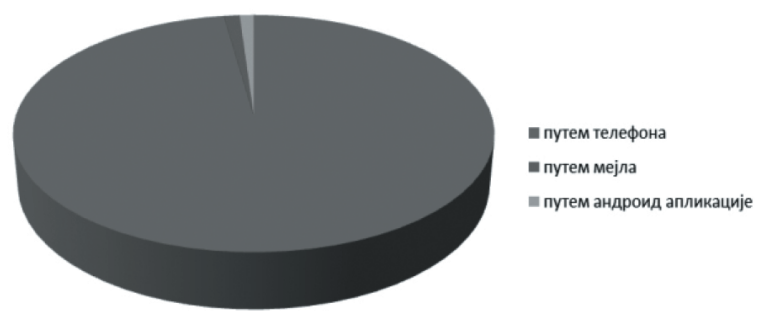

Slika 2. Broj primljenih prijava u 2016. godini [2].

Postoji još jedan karakterističan vid komunikacije između gradske uprave Grada Beograda i građana, a to je mogućnost da se zakažu sastanci sa članovima Gradskog veća i gradonačelnikom. Preko Sektora „Beogradski pozivni centar" građani su se javljali da zakažu sastanak sa članovima Gradskog veća i gradonačelnikom. Za sastanak sa gradonačelnikom prijavljeno je 1490 građana, a za Gradsko veće 315 građana [2].

\section{UPOTREBA INFORMACIONO- KOMUNIKACIONIH TEHNOLOGIJAU KOMUNIKACIJI SA GRAĐANIMA TOKOM VANREDNE SITUACIJE}

Prethodno navedene aplikacije, koje su dostupne građanima Beograda, karakteristične su za redovne okolnosti. Sa druge strane, neke od njih koriste se i u slučaju vanrednih situacija na teritoriji Grada Beograda.

Komunikacija u vanrednim situacijama je od velikog značaja. Česta je pojava da tokom različitih elementarnih nepogoda i drugih nesreća dolazi do prekida u komunikacionim kanalima usled narušavanja rada operatera mobilne i fiksne telefonije. Takođe, narušavanje snabdevanja električnom energijom može dovesti do otežanog ili onemogućenog komuniciranja tokom vanredne situacije. Teritorija Grada Beograda, kao i cele Republike Srbije, poslednjih nekoliko godina bila je ugrožena različitim rizicima usled kojih je morala biti proglašena vanredna situacija. Jedan od najboljih primera za to jesu majske poplave, koje su zahvatile veći deo Republike Srbije tokom maja 2014. godine. Teritorija Grada Beograda takođe je bila ugrožena ovim poplavama, a posebno teritorija gradske opštine Obrenovac. Kada je komunikacija u pitanju, od prvog dana poplava koje su pogodile Grad Beograd postojali su veliki problemi i poteškoće. Značaj informisanja javnosti tokom vanredne situacije bio je očigledan 
tokom majskih poplava 2014. godine. Prema medijskim izveštajima, među najistaknutijim problemima bili su građani koji su bez opravdanih i racionalnih razloga odbijali evakuaciju. Reakcija javnosti koja može varirati od panike do potpune kontrole situacije u velikoj meri zavisi od kapaciteta i sposobnosti kriznih upravljača da pravovremeno i adekvatno podele informacije sa građanima.

Drugi problem koji se javio bilo je da su političari i mediji (uključujući i „nove medije” poput društvenih mreža i raznih blogova i portala) bili deo problema, pre nego deo rešenja krize [6]. „Beokom servis” imao je svoju ulogu u komuniciranju sa građanima i tokom majskih poplava 2014. godine, upotrebom standardnih, kao i modernih informaciono-komunikacionih tehnologija. Uloga se ogledala u vidu centralnog informativnog servisa građana Beograda. Kada se kaže da su prevashodno korišćena standardna sredstva za komunikaciju, prvo se misli na prijem telefonskih poziva onih kojima je bila neophodna pomoć i dalje prosleđivanje informacije nadležnim organima, kao što su Operativni centar Uprave za vanredne situacije u Beogradu, Gradski štab za vanredne situacije Grada Beograda, Crveni krst Srbije i drugi. Tokom poplava 2014.godine, „Beokom servis” vršio je prijem telefonskih poziva građana sa područja Obrenovca kojima je bila potrebna hitna evakuacija. „Beokom servis” vršio je prijem poziva lica koja su evakuisana iz Gradske opštine Obrenovac, a nisu evidentirana u nekom od trijažnih centara u Beogradu (evidentirano je 9906 lica) [4]. Sledeća tabela govori o broju poziva koje su primili zaposleni u „Beokom servisu” tokom majskih poplava 2014. godine.

\begin{tabular}{ll}
\hline Datum & Broj poziva \\
\hline 15.05 .2014$. & 768 \\
\hline 16.05 .2014 & 1537 \\
\hline 17.05 .2014$. & 2597 \\
\hline 18.05 .2014$. & 1620 \\
\hline 19.05 .2014$. & 1348 \\
\hline 20.05 .2014$. & 1923 \\
\hline 21.05 .2014$. & 1148 \\
\hline 22.05 .2014$. & 965 \\
\hline Ukupno & $\mathbf{1 1 9 0 6}$ \\
\hline
\end{tabular}

Tabela 1. Broj ostvarenih poziva sa „Beokom servisom”.

Pored komunikacije sa građanima koja je ostvarena putem telefonskih poziva, zaposleni u „Beokom servisu” primali su veliki broj informacija i elektronskim putem. Tim komunikacionom kanalom, redovno i vanredno pristizale su informacije o trenutnom stanju na poplavljenim područjima, kao i potrebama za evakuacijom i zbrinjavanjem ugroženog stanovništva. Takođe, upotrebom informaciono-komunikacionih tehnologija nastojalo se da se što bolje koordinara aktivnostima komunalnih preduzeća koja su bila angažovana tokom kritičnih dana, kao i kasnije tokom asanacije terena. Na ovaj način „Beokom servis" imao je značajnu ulogu kako ne bi dolazilo do preklapanja upotrebe resursa i mehanizacije. Time se doprinelo značajnim uštedama i u vremenu, a isto tako i u materijalno-finansijskom pogledu. Informacije koje su prosleđivane preko „Beokom servisa” bile su od velike koristi tokom majskih poplava 2014. godine, kako građanima, tako i u radu nadležnih institucija i Gradskog štaba za vanredne situacije Grada Beograda.

\section{PLAN ZA RAZVOJ KOMUNIKACIJE SA GRAĐANIMA UPOTREBOM INFORMACIONO-KOMUNIKACIONIH TEHNOLOGIJA}

Sekretarijat za poslove odbrane, vanrednih situacija, komunikacije i koordinacije odnosa sa građanima, koji je nadležan za komunikaciju sa građanima, konstantno radi na unapređenju svog rada. Kao što se navelo u prethodnim poglavljima, informaciono-komunikacione tehnologije predstavljaju značajan element $\mathrm{u}$ različitim vidovima komunikacije. Poznato je da se u ovoj oblasti ostvaruje stalan razvoj i da je neophodno ispratiti svaki vid promene. Nadležni gradski sekretarijat radi na uvođenju inovacija koje se posebno odnose na informaciono-komunikacione tehnologije, kako bi se ostvarila maksimalna efikasnost i efektivnost u komunikaciji sa građanima.

Neke od najvažnijih planskih aktivnosti koje su planirane za naredni period u ovoj oblasti mogu se navesti:

- Početak uvođenja E-uprave u Grad Beograd koji je planiran da čini jedinstvenu celinu sa E-upravom Republike Srbije;

- Izrada portala Grada Beograda koji bi objedinio postojeći sajt grada, pojedinačne prezentacije jedinica uprave, sve sajtove i prezentacije gradskih opština, preduzeća i ustanova čiji je osnivač Grad Beograd;

- Instalacija i puštanje u rad softvera za potrebe Sektora „Informacioni centar” - Odeljenja za praćenje, koordinaciju i upravljanje, koji ima za cilj evidentiranje i praćenje svih gradilišta u Gradu Beogradu;

- Proširenje saradnje sa gradskim preduzećima „Zelenilo Beograd”, „Beograd put” i „Parking 
servis" u smislu uvođenja ovih preduzeća u Beogradski pozivni centar, kako bi se pozivom jedinstvenog gradskog broja 0800-11-00-11 mogli dobiti operateri ovih preduzeća [3].

Iz navedenog se može zaključiti da Grad Beograd preko svoje organizacione jedinice nadležne za komunikacije i koordinacije odnosa sa građanima nastoji da što više implementira moderne informaciono-komunikacione tehnologije u svoj svakodnevni rad. Postoje i određena organičenja, prevashodno u pogledu finansijskih sredstava. Međutim, jasno je da su ulaganja u ovoj oblasti opravdana i da se bez dobre komunikacije sa građanima ne može očekivati sticanje poverenja u rad gradskih vlasti.

\section{ZAKLJUČAK}

Grad Beograd, u skladu sa svetskim trendovima rada velikih metropola, nastoji da konstantno unapređuje komunikaciju sa svojim građanstvom. Informaciono-komunikacino tehnologije prepoznate su kao koristan alat bez koga je u savremenom društvu nemoguće ostvariti adekvatnu komunikaciju sa građanima. Većina žitelja Grada Beograda, bez obzira na uzrast, koristi mobilne telefone i kompjutere u cilju informisanosti o raznim oblastima. Na osnovu toga, treba im obezbediti informacije koje će biti uvek dostupne i ažurne.

Na osnovu svega iznetog u radu, jasno je da gradske vlasti Grada Beograda sve više koriste moderne informaciono-komunikacine tehnologije kako bi građani uvek mogli doći do pravovremene informacije. Aplikacije poput „Beokom” $i$ „Beograđani” pružaju raznovrsne mogućnosti. Pored prijavljivanja aktuelnih komunalanih problema, kao što je prijavljivanje kvarova, oštećenih puteva i slično, moguće je dati i predloge za unapređenje života na teritoriji Grada Beograda. Takođe, Služba za komunikacije i koordinaciju odnosa sa građanima koristi i društvene mreže u cilju pružanja informacija građanima. Zvaničan veb-portal Beograda je dobro sredstvo za pružanje informacija i komunikacije sa građanima.
Pored aktuelnog korišćenja informaciono-komunikacionih tehnologija, gradska uprava Grada Beograda svojim planom za naredni period predviđa implementiranje i novih sredstava komunikacije putem mobilnih telefona i računarske tehnike. Takođe, i budžetom su predviđena određena sredstva za ulaganje u ovu oblast.

\section{LITERATURA}

[1] Beokom (2016).,Beokom servis” aplikacija dostupna i na IOS-u. Grad Beograd. Preuzeto mart 10, 2017. sa http://www.beograd.rs/lat/beoinfo/1729920 beokom-servis-aplikacija-dostupna-i-na-ios-u/

[2] Glavaš, D. (2017). Izveštaj o radu Službe za komunikacije i koordinaciju odnosa sa građanima u period od 01.01.2016. do 31.12.2016. Gradska uprava Grada Beograda.

[3] Glavaš, D. (2017). Plan rada Sekretarijata za poslove odbrane, vanrednih situacija, komunikacije i koordinaciju odnosa sa građanima za 2017. godinu. Gradska uprava Grada Beograda.

[4] Glavaš, D. (2016).Vanredne situacije, mediji i komunikacije Beokom servisa. Obuka štabova za vanredne situacije u u skladu sa EU mehanizmom civilne zaštite. Beograd

[5] Greenberg, J. i Baron, R. (1998). Behavior in organizations. Želnid. Beograd

[6] Ninković, V. i Kešetović Ž. (2016). Komuniciranje sistema zaštite i spasavanja u vanrednim situacijama izazvanim elementarnim nepogodama. Communication and Media Journal 35 (2015) 109-126. Preuzeto Mart 20, 2016, sa http://scindeks-clanci.ceon.rs/data/pdf/1452-7405/2015/145274051535109 N.pdf

[7] Čudanov, M. i drugi (2006). Projektovanje organizacije u uslovima napretka informacionokomunikacionih tehnologija i sistema. Fakultet organizacionih nauka. Preuzeto mart 25, 2017, sa https://books.google.rs/books/about/Projektovanje_orgaorganiza_u_uslovima_na.html?id=Lv6vsJPLOEC\&redir_esc $=y \& h l=e n$ 


\section{THE USAGE OF CONTEMPORARY ICT RESOURCES FOR THE COMMUNICATION BETWEEN THE CITY AUTHORITY AND THE CITIZENS: THE CITY OF BELGRADE AS THE GOOD PRACTICE EXAMPLE}

\begin{abstract}
:
The communication between citizens and city authority is very important, especially in big cities. Citizens want to know what happen, where problems occur and when it will be solved. On the other side, representatives of city authority will create more confidence among citizens if they provide to them proper information. Nowadays are available a variety of information and communications technology which can facilitate communication between citizens and city authority. The special attention is paid to communication when emergency events or situation occur. The citizens should have opportunity to remark some problem at the territory of the city. In the case of urgency when the time is limited using modern information and communications technology is useful for cooperation between citizens and the city authority. The City of Belgrade, as the capital city of the Republic of Serbia, is one example of good practice in this area. The Belgrade's city authority recognizes need for using modern information and communication technology in the communication with citizens. The special service of the city authority is responsible for these tasks. In its work use few applications which are available for citizens. Also, communication can be achieved through the social networks.
\end{abstract}

\section{Keywords:}

city authority, citizens, information and communication technology, the City of Belgrade, the social networks. 